\title{
Correlates of avifaunal diversity along the elevational gradient of Mardi Himal in Annapurna Conservation Area, Central Nepal
}

Naresh Pandey ${ }^{1}$ (]) Laxman Khanal ${ }^{1,2^{*}}$ (i) and Mukesh Kumar Chalise ${ }^{1,2}$ (])

\begin{abstract}
Background: Patterns of biological diversity and richness can vary along the elevational gradients among mountain systems making it difficult to conclude the general pattern. The drivers of such pattern are also poorly known in the southern flank of the Himalaya due to limited studies. Therefore, we assessed the species richness, seasonal patterns and drivers of avian diversity along an elevational gradient on Mardi Himal trekking trail, a newly open tourist route in Annapurna Conservation Area of the central Himalaya.

Methods: Two surveys (winter and summer seasons of 2019) were conducted from the bank of Seti-Gandaki River confluence (1030 m above sea level, asl) up to the Low Camp (3050 m asl) of the Mardi Himal. The point count method was employed in every $100 \mathrm{~m}$ rise in the elevation. Diversity indices were calculated and bird abundance data on species, sites, seasons and environmental variables were analyzed. Generalized linear model, polynomial regression and ordinary least square regression were performed to examine the importance of environmental factors in shaping the avian richness pattern.
\end{abstract}

Results: A total of 673 individuals of birds belonging to 112 species, of which 72 in winter and 80 in summer, were recorded. We observed a hump-shaped pattern of the overall species richness along the elevational gradient. The richness pattern remained consistent even when explored by season, for winter and summer separately. Diversity indices were found higher during the summer. Elevation and mean monthly temperature in both seasons showed non-linear relation with avian species richness. Precipitation exhibited positive association in summer whereas the same in winter was negatively correlated with avian species richness. Distance to the nearest water source and the nearest human settlement were negatively correlated with the richness of birds. Small-ranged and insectivorous birds were under the strong influence of gradients on climatic variables like temperature and precipitation.

Conclusions: We conclude that the combined effects of multiple factors such as area, gradients of climate (i.e. temperature and precipitation), resource availability and disturbance play an important role in bird diversity and richness pattern along an elevational gradient of a montane environment in Mardi Himal.

Keywords: Annapurna Conservation Area, Avian richness, Central Himalaya, Elevation

*Correspondence: Ikhanal@cdztu.edu.np

${ }^{1}$ Central Department of Zoology, Institute of Science and Technology,

Tribhuvan University, Kathmandu 44613, Nepal

Full list of author information is available at the end of the article

\section{Background}

Besides the latitudinal gradient in biodiversity, there are an increasing number of studies on altitudinal gradients for understanding the spatial variation in biological assortment (He et al. 2019). Birds have been studied extensively to test the diversity patterns at the global (Hawkins and Porter 2001; McCain 2009; Olson et al. 
2009; Voskamp et al. 2017; Somveille et al. 2018) as well as local spatial scales (Ruggiero and Hawkins 2008; Wu et al. 2013; Katuwal et al. 2016; Pan et al. 2016). Avian species richness along the elevational gradient has been found to display four distinct patterns: decreasing richness, low-elevation plateaus, low-elevation plateaus with mid-peaks and mid-elevational peaks (McCain 2009). Among them, hump-shaped pattern with a peak at midelevation is the common one (Rahbek 1995, 2005). However, a decrease in avian species richness with increasing elevation has been reported frequently (Rahbek 1995; Mallet-Rodrigues et al. 2015). The species-specific traits, such as dietary preference, habitat specialization and migratory behavior have a strong influence on species distributions and richness variation across large geographical extents (Carnicer et al. 2011). The avian diversity is correlated with different environmental variables in different parts of the world (Basnet et al. 2016; Voskamp et al. 2017). Therefore, there is no single general pattern of avian species richness along elevational gradients at different areas.

Several factors like land area, geometric constraints, climate, food availability, productivity, evolutionary history, habitat structure and human-induced disturbances play important role in elevational diversity patterns (Colwell et al. 2004; Koh et al. 2006; McCain 2004, 2009; Sanders and Rahbek 2012; Price et al. 2014; Hu et al. 2017b). The larger area harbors more species because of higher habitat heterogeneity and lower extinction rates (Hawkins and Porter 2001). The mid-domain effect, predicts that species richness should tend to peak towards the center of a shared bounded domain due to geometric constraints (Colwell and Lees 2000). Several environmental factors also play a vital role in generating patterns of species richness, among which, the climate influences the diversity in both direct and indirect ways. Climatic factors act as species filter by limiting species distribution on the basis of their physiological tolerances. On the other hand, species distribution can be indirectly influenced by gradients of some climate factors (such as precipitation, temperature), which affect the photosynthetic activity and rates of biological processes in environment (Patterson et al. 1998; Hurlbert and Haskell 2002; Wu et al. 2013). Additionally, the complexity of energy and material transfer (i.e. productivity) can be reflected by species richness patterns (Hawkins et al. 2005, 2007; Koh et al. 2006).

Seasonality has been explained as one of the major factors affecting the avian diversity and dynamics in several ecoregions (Gavashelishvili and McGrady 2006). Seasonal changes in abiotic (e.g. temperatures, precipitation) and biotic (e.g. food resources, species interactions) conditions that vary across elevation gradients force the avian species to ascend or descend avoiding the harsh environmental conditions (Amani et al. 2018). Birds migrate to relocate themselves to areas with a surplus of resources to maximize breeding success and to minimize the risk of high physiological demands and low resource availability (Beuel et al. 2016; Thakuri and Pokhrel 2017; Huang et al. 2019). Extreme shifts in temperature drive the long-distance or trans-continental migration in birds, whereas, fluctuation in the precipitation often causes altitudinal migration within a region (He et al. 2019). Some birds, especially the insectivores, are the habitat specialists and are least dispersive or residential (Zhang et al. 2009; $\mathrm{Hu}$ et al. 2018; He et al. 2019). Therefore, considering the nutritional guild is important while exploring the drivers of seasonal diversity pattern in avian communities.

The Himalayan region, also known as the third pole of the earth, could be an ideal place to investigate the altitudinal pattern of biodiversity as it provides a huge elevational gradient within a short horizontal distance. Placed on the transition between the Oriental and Palearctic zoogeographic realms, the Himalayas are a global biodiversity hotspot (Mittermeier 2004). Additionally, the central Himalayan region has a strong seasonality with hot, wet summer and cold, dry winter. Such contrasting seasonality results in a seasonal variation on habitat structure and resource availability due to which the Himalayan faunal assemblage is diverse utilizing different habitats and resources in different seasons (Sarkar et al. 2018). This region is under the immense threat of climate change-induced habitat destruction and biodiversity loss as the rate of warming in the Himalayas is greater than the global average (Shrestha et al. 2012). Therefore, the Himalaya provides a good context not only to study the impacts of elevational gradient on biodiversity, but also to explore the responses of biodiversity to the short-term seasonal and long-term climatic variations.

Studies on altitudinal gradients of biological diversity in different segments of the Himalaya have reported varied patterns in different taxonomic groups. Floral species almost consistently depict a hump-shaped pattern of richness along the elevational gradient of the Himalaya. For example, trees in the eastern (Acharya et al. 2011a; Rana et al. 2019), central (Vetaas and Grytnes 2002; Bhattarai and Vetaas 2006) and western (Oommen and Shanker 2005) Himalaya; orchids in the eastern and central Himalaya (Acharya et al. 2011c); and, ferns (Bhattarai et al. 2004), medicinal plants (Rokaya et al. 2012) and bryophytes (Grau et al. 2007) in the central Himalaya show a unimodal elevational distribution. However, faunal assemblage along the elevational gradient is not consistent. Invertebrates like ants and butterflies (Bharti et al. 2013; Acharya and Vijayan 2015) show mid-domain effects, whereas, poikilothermic vertebrates such as 
amphibians and reptiles exhibit monotonic decline in richness towards higher elevation (Chettri et al. 2010; Khatiwada et al. 2019). Birds are more complex in elevational richness pattern; they display mid domain effects in some mountains of the Himalaya (Acharya et al. 2011b; Paudel and Šipoš 2014) whereas monotonic decline has been observed in the others (Basnet et al. 2016). Bird diversity gradients in mountains primarily reflect local climatic gradients (Ruggiero and Hawkins 2008); therefore, studies at different mountain segments are important to explore the diversity pattern.

The Annapurna Conservation Area (ACA), one of the largest protected areas of Nepal in the central Himalayan region, is bounded to the north by the dry alpine desert of Dolpo and Tibet, and the Kaligandaki Valley in the south consists of amazing topography like some of the world's highest mountains and the deepest river valley (i.e. Kaligandaki George) in the world (Van Driem 2014). The ACA is recognized as one of the Important Birds and Biodiversity Areas (IBAs) and lies on the global hotspot of bird diversity (BCN 2011). The ACA provides a set of unique habitat and elevational gradients that favor great diversity of flora and fauna and is a treasure house of 1226 species of flowering plants, 105 mammals, 518 birds, 40 reptiles and 23 amphibians (NTNC-ACAP 2020). Previous studies on bird diversity of the ACA have recorded 518 species of birds representing 14 orders, 52 families (Inskipp and Inskipp 2003). Despite having large avian species richness, very few studies have been carried out in the ACA, and majority are focused either on single species (Acharya et al. 2009; Xie et al. 2015; Bansal et al. 2017; Hu et al. 2017a; McCarthy et al. 2018) or in preparation of the checklist only (Grimmett et al. 2016; Baral 2018).

Mardi Himal trekking route is a newly established walking trail in the south-western part of the ACA. To date, no study has been done along this trekking route to determine the biodiversity and their drivers. Being part of the IBAs with an extreme elevational gradient in a short horizontal distance and lying in the north-south migration route of many avian species, this mountain range could be one of the important areas for biodiversity conservation and ecotourism. Additionally, construction of hydropower projects, access roads and trekking trails have started influencing the pristine habitats of the mountain; therefore, a baseline study exploring the present state of biological diversity is deemed must. Therefore, we aimed to (i) explore the avian diversity along an elevational gradient of the Mardi Himal trekking route, (ii) understand the seasonal variation in the elevational pattern of birds in the study area, and (iii) investigate the potential environmental correlates of elevational and seasonal avian diversity patterns.

\section{Methods}

\section{Study area}

Mardi Himal is the southernmost summit (5578 m above sea level, asl) of Annapurna mountain range in the central Himalaya (Fig. 1). Mardi Himal trekking route is a newly opened foot trail which offers visitors with imaging view of Annapurna, Dhaulagiri, Macchapuchre and Manaslu mountain ranges. The route is characterized by the sub-tropical vegetation in the low to subalpine grasslands in the high hills.

The lower areas are on the bank of Seti Gandaki River and Idi River (a tributary of Seti Gandaki). These areas are characterized by the presence of marshy grassland and agricultural field. Major tourist destinations along the trail are Lwang, Lumre, Kuibang, Kalimati, Forest camp, Rest camp and Low camp. In Lumre (1193 $\mathrm{m}$ asl), an upper sub-tropical bioclimatic zone is found which is characterized by presence of vegetation like Schima wallichii, Castanopsis indica, Alnus nepalensis, Holarrhena antidysenterica, etc. Alongside of Mardi trekking route, in Kalimati and Ghalel (1551 to $1862 \mathrm{~m}$ asl), vegetations found are Santalum spp. (dominant), Alnus nepalensis, Juglans regia, Prunus sp., Ficus auriculata, Prunus spp. etc. On the way to the Forest camp (2449 $\mathrm{m}$ asl), there is a dense forest of Osmanthus spp., Rhododendron arboreum, Juniperus squamat, and Quercus semecarpifolia. After forest camp (2600 $\mathrm{m}$ asl), the trail leaves for Low Camp again in the jungle, but the trees soon start to get smaller. On the way to the Low camp (3050 $\mathrm{m}$ asl), there is the presence of vegetation like Osmanthus spp., Juniperus squamata, Rhododendron arboreum, Quercus semecarpifolia, etc.

\section{Research plots}

The lowest elevational limit (1030 m asl) of the survey was set by the confluence site of Seti Gandaki River and Mardi River (i.e. Seti Dovan) (Fig. 2a) and the upper elevational limit (3050 $\mathrm{m}$ asl) was set at the Low-Camp of Mardi Himal (Fig. 2b). Two field surveys of birds were conducted in winter (January-February) and summer (May-June) seasons of 2019. The point count sites were set up with about every $100 \mathrm{~m}$ rise in elevation, which was recorded by Garmin Etrex 10 GPS. Distance from the nearest settlement referred to estimated numerical description of how far the nearest settlement is from the point count site (Additional file 1: Table S1). Distance from the nearest water source referred to numerical description of how far the water bodies like river, ponds, and streams were from the point count site. In this study, the distance to the nearest water source was measured with references to the Mardi River, Modi River and Pau Khola. 


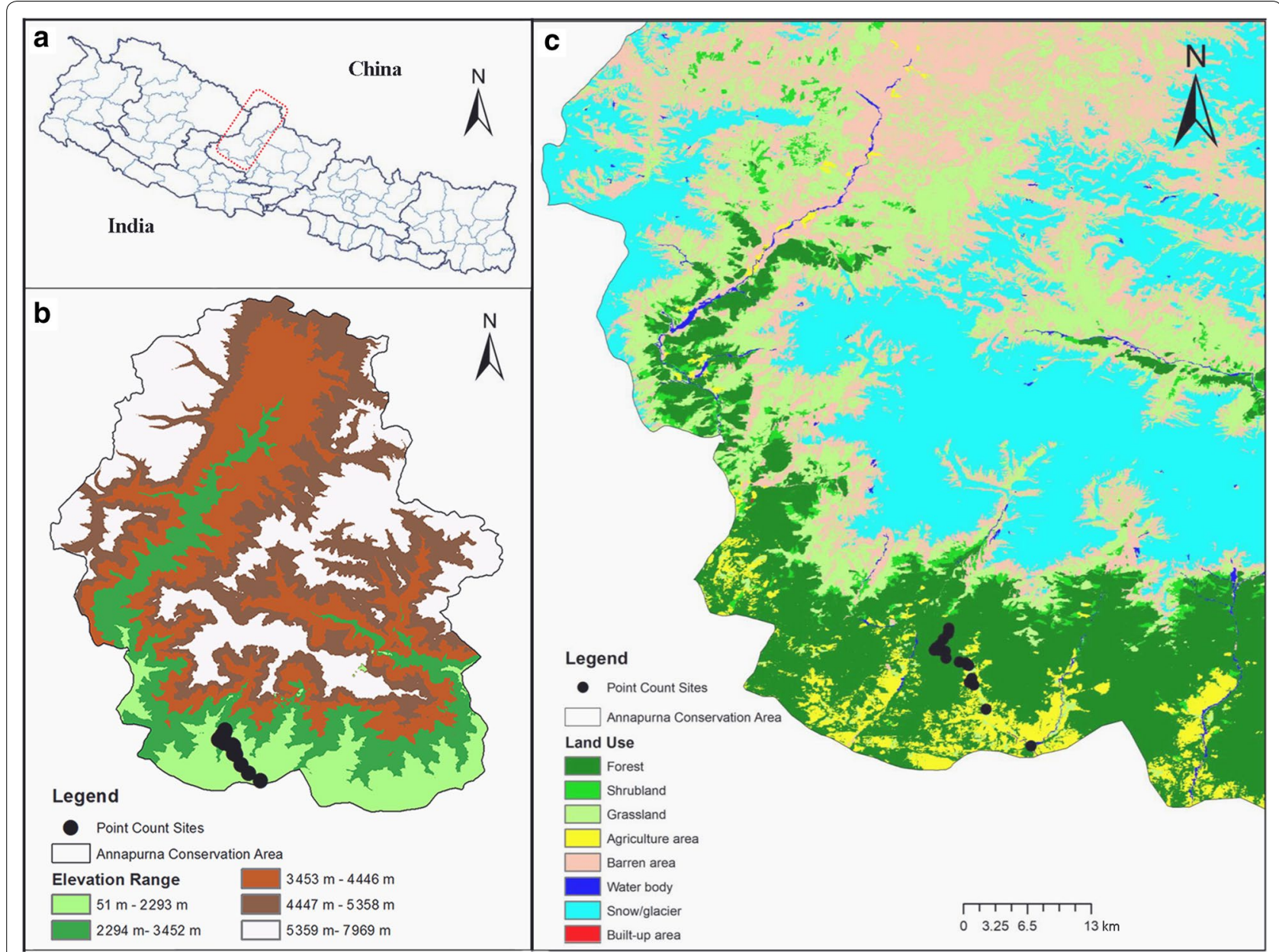

Fig. 1 Map of the study area. a Annapurna Conservation Area (ACA, represented by the red dashed area in the map of Nepal); $\mathbf{b}$ Elevational range in the ACA; and, $\mathbf{c}$ Land use pattern of the south-western region of the ACA where this study was conducted

\section{Bird survey}

Point count method (Bibby et al. 2001) was used for counting the number of bird species. Birds observed and heard within $50 \mathrm{~m}$ radius were recorded from a fixed point in a center (Petit et al. 1995; Ralph et al. 1995; Bötsch et al. 2018). A digital range finder was used to estimate the $50 \mathrm{~m}$ radius. The period of observation for a point varied, based on the habitat where the point liesabout $20 \mathrm{~min}$ in the dense forest to detect rare and inconspicuous species (Aleixo and Galetti 1997; Dos Anjos and Boçon 1999; Krauczuk and Baldo 2004) and $10 \mathrm{~min}$ in an open area like agricultural fields. The birds were observed using Bushnell Falcon $10 \times 50$ wide angle binoculars and photographs were taken using Nikon P900 camera. For the identification of birds, field book Birds of Nepal (Grimmett et al. 2016) was used. Birds were observed from $30 \mathrm{~min}$ after dawn to 11:30 AM, and again from 3:00 PM till $30 \mathrm{~min}$ before sunset as practiced by He et al. (2019).

\section{Environmental variables}

Due to the unavailability of climate data from uniformly distributed weather stations in the central Himalaya, the climate data of resolution $1 \mathrm{~km} \times 1 \mathrm{~km}$ on mean monthly precipitation and mean monthly temperature for the coordinates of bird-count points were extracted from the WorldClim database (https://www.worldclim. org/bioclim). The WorldClim generates environmental data through interpolation of average monthly climate data from nearby weather stations (Hijmans et al. 2005) and such data have been shown to be correlated with the measured temperature data (Dunn et al. 2007b; Machac et al. 2011). Considering the coarse resolution of climatic variables from the WorldClim, effects of possible spatial autocorrelation were tested using Global Moran's I in ArcGIS 10.4. The results showed significant spatial autocorrelation (i.e. Moran's Index $=0.592, z$-score $=5.438$ and $P$-value $=0.00)$, therefore, a weight matrix was obtained by using queen contiguity criteria in GeoDa 


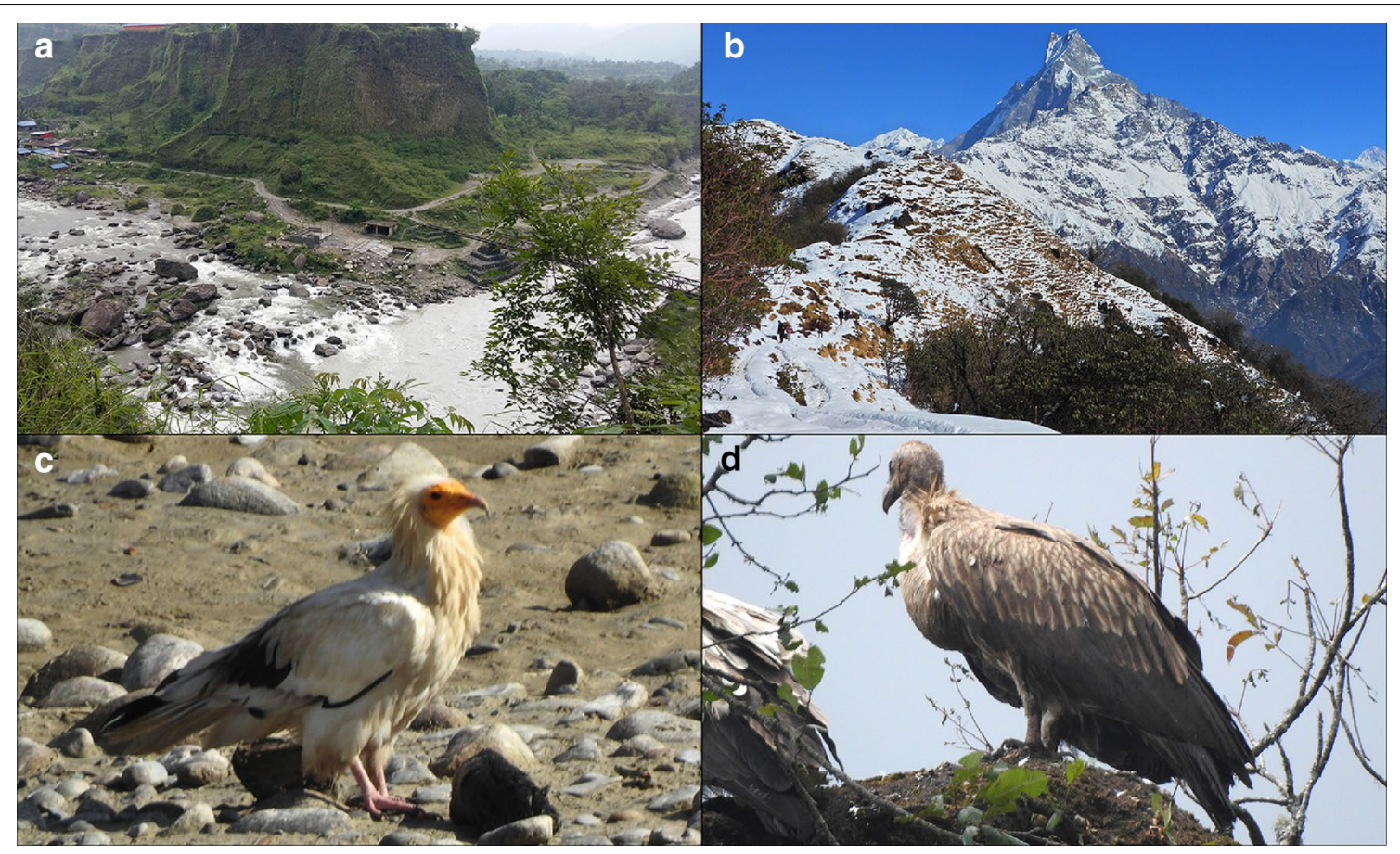

Fig. 2 Photo plates showing a the start point of the bird survey, the confluence of Seti River and Mardi River (1030 m asl); $\mathbf{b}$ the snow-covered upper elevational limit for the study (3050 $\mathrm{m}$ asl) near the Low-Camp; c an adult Egyptian Vulture (Neophron percnopterus), one of the globally endangered birds recorded at $1108 \mathrm{~m}$ asl; and, d a juvenile Himalayan Vulture (Gyps himalayensis) observed at $2263 \mathrm{~m}$ asl along the Mardi Himal trekking trail

v.1.14 (Anselin et al. 2006) and three statistical models, i.e., ordinary least square (OLS) regression model, Spatial Error Model and Spatial Lag Model, were tested to the data. Both the Lagrange Multiplier (lag) $(P=0.933)$ and Lagrange Multiplier (error) $(P=0.927)$ results were not significant; therefore, the OLS regression was performed to examine the potential of individual factors to explain elevational patterns of species richness as suggested by Anselin (2005). Polynomial regression (richness as a function of elevation, elevation ${ }^{2}$ and elevation ${ }^{3}$ ) was performed to assess the elevational distribution patterns of species richness for both the seasons guided by the corrected Akaike information criterion (AICc) value, with smaller AICc values indicating a better fit. Before performing the multiple regression, normality and homoscedasticity for each variable were tested. Then, the selected factors were tested with multiple regressions to compare their influence on species richness patterns. The best model was selected from all possible combinations, guided by the lowest AICc.

The effect of area on avian species richness was tested with the planimetric area for each $100 \mathrm{~m}$ elevational bands in the Mardi Himal calculated from the 30-m resolution Shuttle Radar Topography Mission-Digital Elevation Model (STRM-DEM) data using ArcGIS 10.4. To account the effects of variation in productivity on the elevational richness pattern of birds, we used the normalized difference vegetation index (NDVI) data. The NDVI of $30 \mathrm{~m}$ resolution and less than $10 \%$ cloud cover for the winter season of 2019 was retrieved from Landsat-8 OLI/ TIRS image downloaded from the US Geological Survey (https://espa.cr.usgs.gov).

\section{Data analysis}

Observed birds were classified into four feeding guildscarnivorous, frugivorous, omnivorous and insectivorous, based on the diet descriptions available in Grimmett et al. (2016). Further, the birds of Mardi Himal trekking routes were categorized as residential, winter visitors and summer visitors (Additional file 2: Table S2) based on Grimmett et al. (2016).

The collected data from the field survey were at first entered in excel datasheet and then Shannon-Wiener diversity indices were calculated using "Vegan" package (Oksanen et al. 2013) in R software ( $R$ Core Team 2017). In order to assess the effect of elevational range size of the species on richness patterns, bird species were divided into two categories: "large-ranged species", with an elevational range equal to or above the median size $(170.5 \mathrm{~m})$; and "small-ranged species", with elevational 
ranges below the median size following the method of Wu et al. (2013) (Additional file 3: Table S4). We used the generalized linear model (GLM; function 'glm' in R) with normal distribution and an identity link function in $\mathrm{R}$ software. The relationships between the avian richness and environmental variables were established by polynomial regression and ordinary least square (OLS) regression performed in the PAST v.3.14 (Hammer et al. 2001). Multiple regression and best model selection were performed using "MuMIn" package (Barton 2009) in R software (R Core Team 2017).

\section{Results}

\section{Avian diversity in the Mardi Himal}

A total of 673 individuals of birds belonging to 112 species from 13 orders and 35 families were recorded from 21 point-count sites during two surveys of summer and winter seasons (Additional file 2: Table S2). Globally endangered species like Egyptian Vulture (Neophron percnopterus) (Fig. 2c), near threatened species like River Lapwing (Vanellus duvaucelii), Himalayan Vulture (Gyps himalayensis) (Fig. 2d) and the endemic bird of NepalSpiny Babbler (Turdoides nipalensis), were recorded. The number of avian species observed at a single point count station varied from two to 20 and the number of individuals at each point ranged between five and 42 . Resident species $(n=80)$ had greater species richness than migratory birds $(n=32)$. Among the feeding guilds, the highest number of insectivorous species (58) was recorded followed by frugivorous (26), omnivorous (14) and carnivorous (14) birds. The highest species richness (20 species) and Shannon-Wiener diversity index $(H=2.661)$ was recorded in point count site 9 (p9) at an elevation of $1862 \mathrm{~m}$ asl. The least value of diversity index $(H=1.379)$ was observed at point count site 20 (p20, $2945 \mathrm{~m}$ asl) (Additional file 3: Table S3).

\section{Seasonal variation in avian diversity}

Bird species richness varied with seasons. Of the total 112 species observed, 40 species were found only on the summer season, 32 species were found only on the winter season and 40 species were common to both the seasons. However, higher abundance of birds was found in winter $(n=340)$ than in summer $(n=333)$. Species like Himalayan Vulture (Gyps himalayensis) (15), Dark-breasted Rosefinch (Carpodacus nipalensis) (14), Grey Bushchat (Saxicola ferreus) (13), Oriental Turtle Dove (Streptopelia orientalis) (11) and Black Drongo (Dicrurus macrocercus) (10) were abundantly found in summer season, whereas, House Sparrow (Passer domesticus) (15), Black-throated Tit (Aegithalos concinnus) (13), Speckled Wood Pigeon (Columba hodgsonii) (12), Barn Swallow (Hirundo rustica) (11) and Rufous Sibia (Malacias capistratus) (10) were abundant in winter. Most abundant species in both seasons were Red-vented Bulbul (Pycnonotus cafer) (52) and Himalayan Bulbul (Pycnonotus leucogenys) (50). Among the resident birds $(n=80), 55 \%$ had the range size below the median value and $45 \%$ had the larger range size. Most abundant birds from the summer season had wider elevational range than that of the winter season (Fig. 3; Additional file 3: Table S4). With respect to feeding guilds, insectivorous and frugivorous species were more abundant in summer than that of the winter. But, in winter season, richness of carnivorous and omnivorous species was higher compared to that of the summer (Fig. 4).

\section{Environmental factors affecting avian diversity}

Among the environmental variables tested, the generalized linear model (GLM) showed their differential relations with avian species richness for two seasons. For the summer season, avian richness differed significantly with increasing area, distance to the nearest settlement, precipitation (mean) and temperature (mean). However, in the winter, there was a significant difference in species richness of birds only with increasing area, precipitation (mean) and temperature (mean) (Table 1). The NDVI for the winter season did not seem to have significant effects in shaping overall avian species richness.

Area, precipitation (both seasons) and mean temperature of the summer showed significant role in shaping the richness of small-ranged resident bird species $(n=44)$, whereas area, distance to the nearest water source, mean precipitation of the summer and NDVI showed significant role for large-ranged resident species $(n=36)$ (Table 1). Among the feeding guilds, area, mean precipitation and mean temperature of the summer showed significant role to the insectivores. The mean precipitation of the winter showed significant role for frugivores, whereas mean temperature of the winter appeared to have significant role in shaping carnivore richness. However, none of these environmental factors seemed to have significant role in shaping the richness of omnivorous bird species (Additional file 3: Table S5). The polynomial regressions of species richness patterns along the elevational gradients demonstrated that total species, species richness of the summer and species richness of the winter better fit a cubic function across elevations (Table 2; Fig. 5).

Other factors like precipitation (mean), distance to the nearest water source and distance to the nearest settlement showed linear relationship with bird richness, so, we performed ordinary least square (OLS) regression analysis at $95 \%$ confidence interval (bootstrapped at $N=1999$ ). The precipitation (mean) appeared to play significant role in shaping the bird richness and 


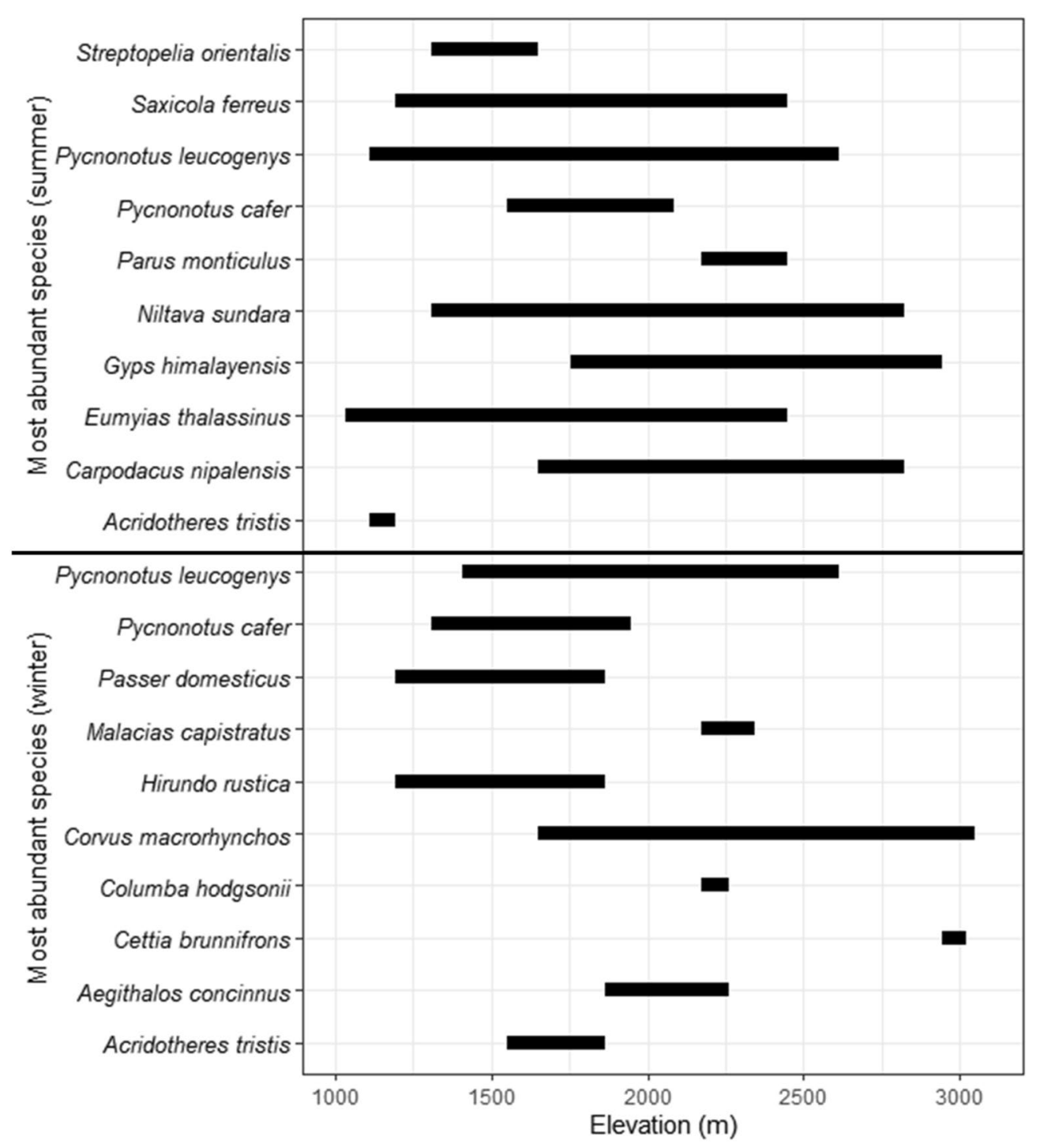

Fig. 3 Elevational distribution range of the most abundant 10 bird species for each of the summer and winter season from the Mardi Himal

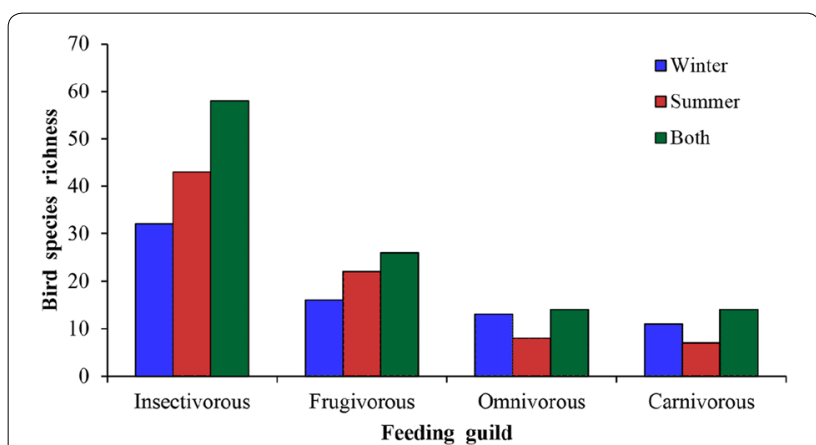

Fig. 4 Species richness of birds for different feeding guilds in summer and winter seasons is positively correlated during summer and negatively correlated during winter (Fig. 6). Similarly, distance to the nearest water source had significantly negative association during summer season. Distance to the nearest settlement didn't show any significant role in determining avian richness. The best fit models varied between the season and among the different groups of birds (Table 3). Precipitation (summer or winter) in combination with area or distance to the nearest source of water revealed as the best model for overall seasonal richness, range-based groups and frugivores. Whereas, temperature in combination with precipitation and area best predicted the richness pattern of carnivores, insectivores and omnivores. 
Table 1 Generalized linear model (GLM) with normal distribution and identity link function test showing the effects of different environmental factors on avian richness pattern in Mardi Himal trekking route

\begin{tabular}{|c|c|c|c|c|}
\hline Season & Environmental factor & Slope (a) & Intercept (b) & $P$ value \\
\hline \multirow[t]{5}{*}{ Summer } & Area & 0.125 & 8.348 & 0.001 \\
\hline & Distance to the nearest water source & -0.004 & 22.564 & 0.015 \\
\hline & Distance to the nearest settlement & -0.007 & 18.8 & 0.147 \\
\hline & Mean precipitation & 0.041 & 0.094 & $<0.001$ \\
\hline & Mean temperature & 1.734 & -18.478 & 0.015 \\
\hline \multirow[t]{6}{*}{ Winter } & Area & 0.132 & 8.229 & 0.003 \\
\hline & Distance to the nearest water source & -0.003 & 21 & 0.109 \\
\hline & Distance to the nearest settlement & -0.003 & 17.417 & 0.57 \\
\hline & Mean precipitation & -1.676 & 41.096 & $<0.001$ \\
\hline & Mean temperature & 1.487 & 2.175 & 0.018 \\
\hline & NDVI & -7.727 & 21.162 & 0.057 \\
\hline \multirow[t]{8}{*}{ Small-ranged species } & Area & 0.086 & 2.63 & 0.003 \\
\hline & Distance to the nearest water source & -0.002 & 12.09 & 0.024 \\
\hline & Distance to the nearest settlement & -0.004 & 9.394 & 0.274 \\
\hline & Mean precipitation (summer) & 0.052 & 1.164 & 0.366 \\
\hline & Mean precipitation (winter) & -0.772 & 16.15 & $<0.001$ \\
\hline & Mean temperature (summer) & 0.579 & -8.33 & 0.037 \\
\hline & Mean temperature (winter) & 0.64 & -1.45 & 0.051 \\
\hline & NDVI (winter) & -3.28 & 6.78 & 0.65 \\
\hline \multirow[t]{8}{*}{ Large-ranged species } & Area & 0.138 & 8.62 & 0.005 \\
\hline & Distance to the nearest water source & -0.003 & 22.53 & 0.093 \\
\hline & Distance to the nearest settlement & -0.004 & 18.53 & 0.511 \\
\hline & Mean precipitation (summer) & 0.253 & -0.95 & 0.004 \\
\hline & Mean precipitation (winter) & -0.95 & 22.44 & $<0.001$ \\
\hline & Mean temperature (summer) & 0.92 & -9.67 & 0.073 \\
\hline & Mean temperature (winter) & 0.706 & 1.58 & 0.039 \\
\hline & NDVI (winter) & -4.51 & 11.14 & 0.55 \\
\hline
\end{tabular}

Values marked in italics are statistically significant at $P<0.05$

Table 2 Polynomial regression of species richness patterns along the elevational gradient

\begin{tabular}{llll}
\hline Regressions & $\begin{array}{l}\text { Total species } \\
\text { richness }\end{array}$ & $\begin{array}{l}\text { Species richness } \\
\text { (summer) }\end{array}$ & $\begin{array}{l}\text { Species } \\
\text { richness } \\
\text { (winter) }\end{array}$ \\
\hline First order $r^{2}$ & $0.253^{*}$ & $0.264^{*}$ & $0.2006^{*}$ \\
AIC & 4614 & 1200 & 1414.1 \\
Second order $r^{2}$ & $0.472^{*}$ & $0.416^{*}$ & $0.452^{*}$ \\
AIC & 3263.4 & 956.5 & 972.14 \\
Third order $r^{2}$ & $0.5608^{*}$ & $0.448^{*}$ & $0.621^{*}$ \\
AIC & 2722 & 906.7 & 717.3 \\
\hline
\end{tabular}

Italic letters indicate the best model based on the lowest corrected Akaike information criterion (AICc) values

*Significant at $P<0.05$

\section{Discussion}

\section{Avian diversity in Mardi Himal}

This study explored the avian diversity along the elevational gradient of Mardi Himal trekking route in the south-western region of the Annapurna Conservation Area in central Nepal. From the point-count survey of two seasons (summer and winter), we recorded a total of 112 species of birds belonging to 13 orders and 35 families. We observed that insectivorous form is the most species-rich feeding guild in the Mardi Himal, which is consistent to many other studies in birds (Herzog et al. 2005; De Bonilla et al. 2012; Katuwal et al. 2016). About $29 \%(32 / 112)$ of the bird species observed in Mardi Himal are migratory birds which is almost similar to the observation of Neupane et al. (2020) along the Kaligandaki River basin of the ACA but lesser proportion than that of the overall contribution of migrants $(38 \%$, 336/884) (Grimmett et al. 2016) in the avian diversity of Nepal. A lesser proportion of the migratory birds in the avian community of the Mardi Himal might be because most of the migrant birds to Nepal are wetland species visiting the lowland Terai. Additionally, some geophysical attributes of the Mardi Himal such as high precipitation and evapotranspiration, dense coverage of vegetation in 

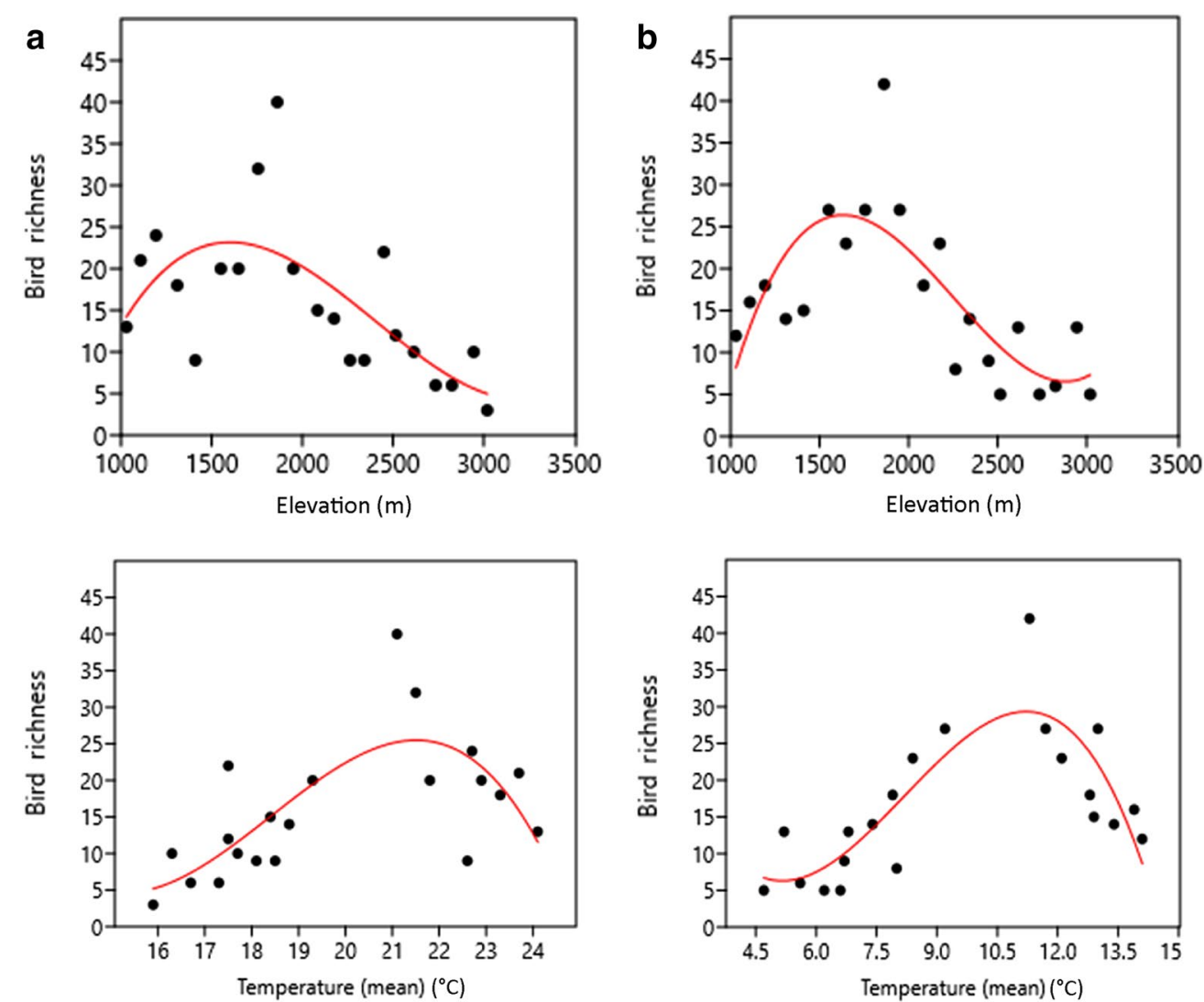

Fig. 5 Relationship between bird richness and environmental factors (elevation and mean temperature) in a summer season and $\mathbf{b}$ winter season in Mardi Himal trekking route, ACA

the protected forest and availability of food resources for all types of feeding guilds might support year-round suitable habitats to the avian community.

\section{The elevational pattern of avian assemblage}

Avian fauna showed a clear variation in species richness along the elevational gradient having a peak at mid-elevation and decreasing onward with increasing elevation. These results are in line with previous studies for birds in the Himalaya (McCain 2009; Acharya et al. 2011b; Paudel and Šipoš 2014; Katuwal et al. 2016; Hu et al. 2018) exhibiting a hump-shaped pattern. The avian richness in Mardi Himal peaked at around $1900 \mathrm{~m}$ asl, much similar to the study in the eastern Himalaya (2000 m) (Acharya et al. 2011b) but lower than that of other mountains in the central Himalaya (2600-3000 m asl) (Katuwal et al. 2016), generalized analysis to the entire Nepal Himalaya (2800 $\mathrm{m}$ asl) (Paudel and Šipoš 2014) and Gyirong Valley in China (2400-3000 m asl) (Hu et al. 2018). Richness pattern similar to that of the wet eastern Himalaya might be associated to the high annual precipitation received at the mid-elevations of Mardi Himal lying on the windward side of the Annapurna Himalayan range proximal to the Pokhara valley, the highest precipitating area of Nepal. Results from our study reveal that precipitation and temperature have significant roles in shaping the avian richness pattern. Such local environmental drivers shaping the elevational richness pattern have been described from the Himalaya and nearby mountains in other taxa, including small mammals (Chen et al. 2017, 2020), frogs (Fu et al. 2006) and plant species (Rahbek 2005; Bhattarai and Vetaas 2006; Acharya et al. 2011a). Another reason behind the hump-shaped pattern of avian richness in Mardi Himal might be the higher range overlap among the resident species at about $1500-2000 \mathrm{~m}$ asl, because this phenomenon, especially with large-ranged species has been described as the major driver of the middomain effect or a hump-shaped richness pattern (Dunn et al. 2007a).

In addition to the factors favoring higher richness at the mid-elevation, there are multiple factors which limit avian richness in the lower and upper extremes of the elevation gradient in the Mardi Himal. Human disturbance can cause a decrease in species richness by habitat 

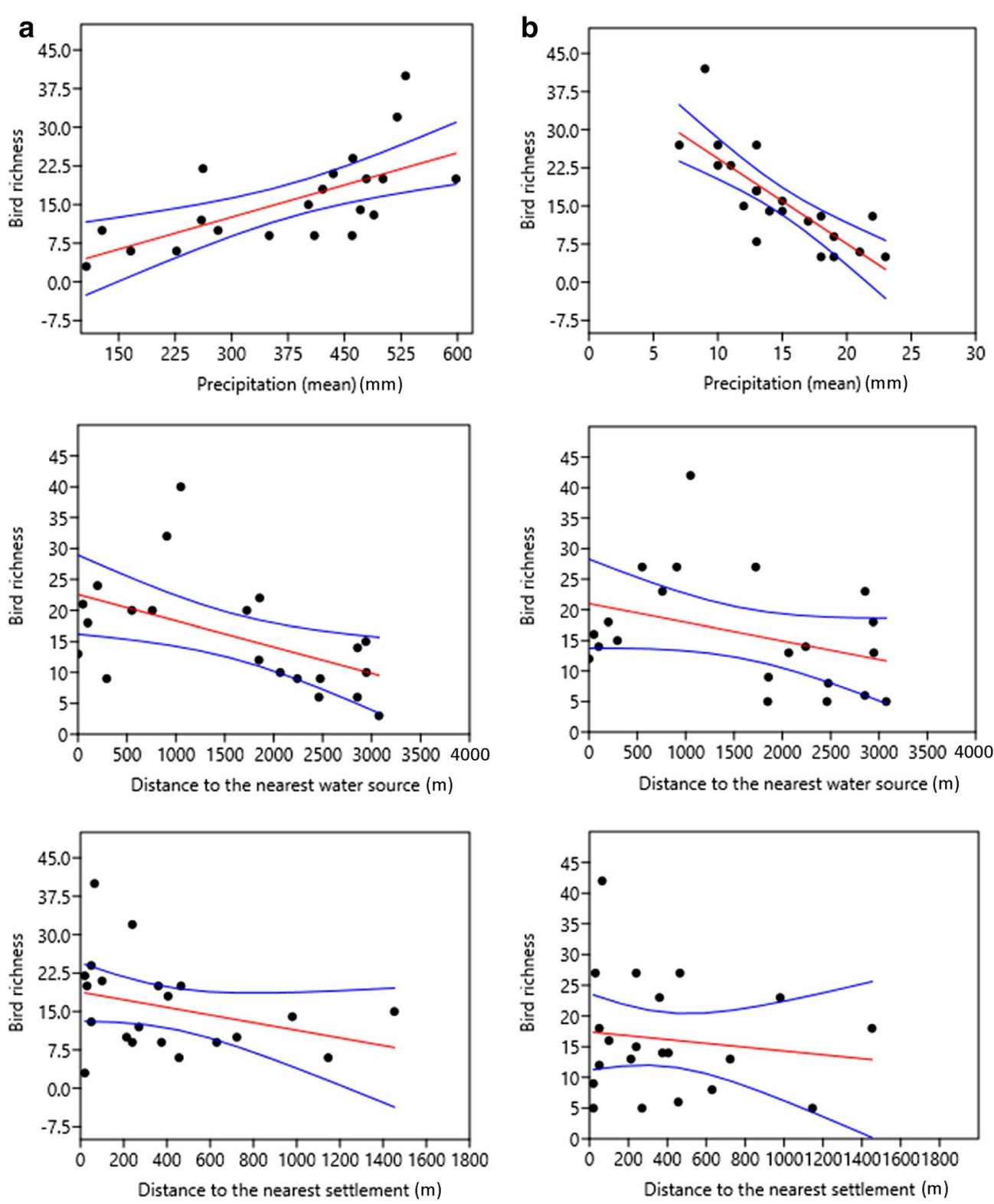

Fig. 6 Relationship between bird richness and different factors (mean precipitation, distance to the nearest water source and distance to the nearest settlement) in $\mathbf{a}$ summer season and $\mathbf{b}$ winter season in Mardi Himal trekking route, ACA

loss, land-use change, species invasions, etc. (Murphy and Romanuk 2014). The scale of effects of disturbance on diversity differs among taxa in relation to their mobility and nutritional guild specificity (Hamer and Hill 2000; Zhang et al. 2013). The lesser avian diversity in lower elevations of Mardi Himal might be due to the human disturbances like vehicles, construction works, etc. from the ongoing hydropower projects because such anthropogenic activities have been reported to cause negative impacts on the avian species richness elsewhere too (Reijnen et al. 1995; Halfwerk et al. 2011). Studies from around the globe have found that habitat specialist bird species are most susceptible to forest disturbances (Stouffer and Bierregaard 1995; Sekercioglu 2012; Arcilla et al. 2015; Pavlacky et al. 2015; Asefa et al. 2017). The Mardi Himal trekking route has a higher proportion of residential insectivorous birds, and such habitat specialists and the least dispersive insectivores (Zhang et al. 2009) might have been under the influence of humaninduced disturbances and habitat alteration at the low elevation areas. The lowest species richness of birds above $2500 \mathrm{~m}$ asl might be attributed to lesser area, 
Table 3 Results of model selection (best model) for avian richness along elevational gradients in Mardi Himal Trekking route

\begin{tabular}{|c|c|c|c|c|c|}
\hline Species group & Best model & $R^{2}$ & Adjusted $R^{2}$ & AICc & $P$ value \\
\hline Overall species (summer) & $D W+P(S)$ & 0.44 & 0.38 & 146.6 & 0.005 \\
\hline Overall species (winter) & $A+P(W)$ & 0.63 & 0.59 & 139.68 & $<0.001$ \\
\hline Large-ranged species & $D W+P(W)$ & 0.54 & 0.49 & 150.71 & $<0.001$ \\
\hline Small-ranged species & $D W+P(S)$ & 0.42 & 0.36 & 133.82 & 0.006 \\
\hline Frugivorous & $A+P(W)$ & 0.39 & 0.32 & 154.32 & 0.011 \\
\hline Carnivorous & $P(W)+T(W)$ & 0.44 & 0.38 & 80.34 & 0.004 \\
\hline Insectivorous & $A+T(W)$ & 0.28 & 0.2 & 137.79 & 0.049 \\
\hline Omnivorous & $\mathrm{DW}+\mathrm{P}(\mathrm{W})+\mathrm{T}(\mathrm{W})$ & 0.32 & 0.21 & 121.46 & 0.072 \\
\hline
\end{tabular}

$A$ land area of $100 \mathrm{~m}$ elevational band, $D W$ distance to the nearest water source, $P(S)$ mean precipitation of summer season, $P(W)$ mean precipitation of winter season, $T(W)$ mean temperature of winter season

minimum precipitation, harsh climatic conditions, lesser productivity and resource limitations are the major drivers of lower species richness at the peaks of mountain ranges (Acharya et al. 2011b; Hu et al. 2018). BCN (2011) described lesser species richness in meadows of the central Himalaya that is associated with overgrazing and less availability of food.

\section{Seasonal variation in avian assemblage}

We observed insignificantly higher avian richness and diversity in the summer $\left(n=80, H_{\mathrm{s}}=3.95\right)$ than in the winter season $\left(n=72, H_{\mathrm{w}}=3.76\right)$, whereas bird abundance was higher in the winter than in the summer. Contribution of the seasonal migrants to higher richness and abundance of birds in a particular season has been observed in multiple studies at varied geographical conditions (Werema and Howell 2015; Gomes et al. 2017; Tzortzakaki et al. 2017; Muhammad et al. 2018), however, such effects are not prominent when a majority of the avifauna is dominated by common resident birds (Nam et al. 2019). Small seasonal variation on the abundance of birds in the study area might be accounted for the larger proportion $(71.4 \%, 80 / 112)$ of the residential species. Despite having almost similar species richness in two seasons, higher heterogeneity might have resulted in the higher values of diversity indices for the summer season. The amount of energy available in a system, often measured as the primary productivity, which is generally lowered during the cold and dry winter season is thought to be one of the major determinants of variation in species diversity (Bailey et al. 2004). However, we observed inconspicuous variation in the elevational and seasonal distribution of NDVI, a proxy of the productivity, except at the upper extremes of the study gradient. Lowered bird richness in the winter season in the montane environment is due to unfavorable climatic conditions, shortage of food and higher predation risk (Maphisa et al. 2016).
The range analysis in this study also revealed that bird species move downslope or away from the snowy mountain during the winter and thus richness and abundance of the avian fauna lowers at higher elevations.

\section{Environmental correlates of avian assemblage}

Temperature and precipitation exhibited a strong association to the avian richness in the Mardi Himal. Their effects were stronger in shaping species richness pattern of small-ranged birds than that of the large-ranged species. This result is consistent with the original proposition of Ruggiero and Hawkins (2008) that the contemporary climate has strong relationships with species richness patterns of small-ranged, montane birds. Climatic variables such as mean daily temperature and precipitation are widely supported environmental predictors of biodiversity patterns (Shoo et al. 2005; Peters et al. 2016) as they set limits on species distributions depending upon their physiological tolerances (He et al. 2019). Besides physiological tolerances, gradients of precipitation and temperature indirectly influence species distribution pattern by affecting photosynthetic activity and rates of biological processes in environment (Patterson et al. 1998; Hurlbert and Haskell 2002; Wu et al. 2013). However, such effects of climatic variables are not equal among different groups. Among the feeding guilds, insectivore assemblage showed a strong association with the climatic factors than other groups. Insectivorous birds are the habitat specialists and are least dispersive or residential (He et al. 2019), hence are more specialized to the microhabitats.

Mardi Himal provides a range of habitat types, which in turn provide different kinds of food for various birds facilitating their heterogeneous assemblage. We observed a negative correlation of species richness with distance to the nearest water source which was consistent with findings of Shwartz et al. (2008). Li et al. (2013) concluded 
that avian species richness is hump-shaped function of energy availability, but a linear function of water availability and further emphasized that water availability has strong effects on plant richness and weaker effects on vertebrate richness. Likewise, Currie (1991) observed that the richness of vertebrates (birds, mammals, amphibians and reptiles) is more influenced by energy while the same in the tree species is more influenced by water availability. Influence of water on plants presumably affects vertebrate species richness staunchly since plants are the chief source of food and habitat and fulfill their dietary requirements and niche (Kissling et al. 2007). The NDVI, used as the proxy of productivity measurement did not show a significant association to the overall bird species richness but was significant for the large-ranged bird species. Similar findings were reported for small mammals in Yulong mountain, China (Chen et al. 2020). However, we could not test the effects of NDVI in avian richness for the summer/rainy season due to the unavailability of high-quality satellite images with lesser cloud coverage. We acknowledge that first-hand climatic data using climate data loggers and vegetation survey would aid to make a clear understanding of avian species richness along the elevational gradient of the Mardi Himal.

\section{Conclusions}

This study from the newly opened trekking route in Mardi Himal of central Nepal observed high diversity of the avian fauna. The assemblage of avian species in the Mardi Himal displays a hump-shaped pattern along the elevational gradient. Climatic factors like temperature and precipitation have a strong influence in avian richness and diversity pattern. We conclude that the bird diversity and richness in a montane environment with strong seasonality is determined by the combined effects of different environmental factors such as elevation, gradients of climate (i.e. temperature and precipitation), resource availability and disturbance.

\section{Supplementary information}

Supplementary information accompanies this paper at https://doi. org/10.1186/s40657-020-00217-6.

Additional file 1: Table S1. The 21 point-count stations along the Mardi Himal Trekking route with GPS details and distances to the nearest water source and settlement.

Additional file 2: Table S2. The checklist of bird species recorded from the Mardi Himal trekking route.

Additional file 3: Table S3. The 21 point count stations along the Mardi Himal Trekking route with avian diversity indices. Table S4. Range-size classification of the residential birds observed in Mardi Himal Trekking route. Table S5. Generalized linear model (GLM) summary showing the effects of different environmental factors to feeding guild wise bird species richness in Mardi Himal trekking route.

\section{Acknowledgements}

We would like to thank Department of National Parks and Wildlife Conservation, Government of Nepal, and Annapurna Conservation Area Project, Pokhara for granting research permission. We are thankful to Dr. Bipin Acharya from the Sun Yat-Sen University China for his support in manuscript improvement. We thank Mr. Shiva Prasad Bhandari of Mardi Himal Eco-Village, Sanju Sharma, Neeti Chapagain, and K. Deepak Singh for their support in field works.

\section{Authors' contributions \\ NP and LK designed the study and NP conducted the field surveys. NP and LK performed the data analysis and wrote the manuscript. MKC supervised the research and provided multiple revisions in the early stages of writing. All authors read and approved the final manuscript.}

\section{Funding}

Not applicable.

\section{Availability of data and materials}

The datasets supporting the conclusions of this article are included within the article and its additional files.

\section{Ethics approval and consent to participate}

Permits for this study were obtained from the Department of National Parks and Wildlife Conservation, Kathmandu and Annapurna Conservation Area Project Office, Pokhara. This study does not involve any handling of endangered or protected species.

\section{Consent for publication}

Not applicable.

\section{Competing interests}

The authors declare that they have no competing interests.

\section{Author details}

${ }^{1}$ Central Department of Zoology, Institute of Science and Technology, Tribhuvan University, Kathmandu 44613, Nepal. ${ }^{2}$ Nepal Biodiversity Research Society (NEBORS), Lalitpur 44700, Nepal.

Received: 25 March 2020 Accepted: 6 August 2020

Published online: 02 September 2020

\section{References}

Acharya BK, Vijayan L. Butterfly diversity along the elevation gradient of Eastern Himalaya, India. Ecol Res. 2015;30:909-19.

Acharya R, Cuthbert R, Baral HS, Shah KB. Rapid population declines of Himalayan Griffon Gyps himalayensis in Upper Mustang, Nepal. Bird Conserv Int. 2009;19:99-107.

Acharya BK, Chettri B, Vijayan L. Distribution pattern of trees along an elevation gradient of Eastern Himalaya, India. Acta Oecol. 2011a;37:329-36.

Acharya BK, Sanders NJ, Vijayan L, Chettri B. Elevational gradients in bird diversity in the Eastern Himalaya: an evaluation of distribution patterns and their underlying mechanisms. PLOS ONE. 2011 b;6:e29097.

Acharya KP, Vetaas OR, Birks HJB. Orchid species richness along Himalayan elevational gradients. J Biogeogr. 2011c;38:1821-33.

Aleixo A, Galetti M. The conservation of the avifauna in a lowland Atlantic forest in south-east Brazil. Bird Conserv Int. 1997;7:235-61.

Amani M, Salehi B, Mahdavi S, Brisco B. Spectral analysis of wetlands using multi-source optical satellite imagery. ISPRS J Photogramm. 2018;144:119-36.

Anselin L. Exploring spatial data with GeoDaTM: a workbook. Urbana: Center for Spatially Integrated Social Science; 2005.

Anselin L, Syabri I, Kho Y. GeoDa: an introduction to spatial data analysis. Geogr Anal. 2006;38:5-22.

Arcilla N, Holbech LH, O'Donnell S. Severe declines of understory birds follow illegal logging in Upper Guinea forests of Ghana, West Africa. Biol Conserv. 2015;188:41-9. 
Asefa A, Davies AB, McKechnie AE, Kinahan AA, van Rensburg BJ. Effects of anthropogenic disturbance on bird diversity in Ethiopian montane forests. Condor: Ornithol Appl. 2017;119:416-30.

Bailey SA, Horner-Devine M, Luck G, Moore L, Carney K, Anderson S, et al. Primary productivity and species richness: relationships among functional guilds, residency groups and vagility classes at multiple spatial scales. Ecography. 2004;27:207-17.

Bansal S, Katyal D, Garg JK. A novel strategy for wetland area extraction using multispectral MODIS data. Remote Sens Environ. 2017:200:183-205.

Baral R. Birds of annapurna conservation area. Pokhara, Nepal: National Trust for Nature Conservation, Annapurna Conservation Area Project; 2018

Barton K. Mu-MIn: Multi-model inference. R Package Version 0.12.2/r18. 2009. http://R-Forge.R-project.org/projects/mumin/.

Basnet TB, Rokaya MB, Bhattarai BP, Munzbergova Z. Heterogeneous landscapes on steep slopes at low altitudes as hotspots of bird diversity in a Hilly Region of Nepal in the Central Himalayas. PLoS ONE. 2016;11:e0150498.

BCN D. The state of Nepal's birds 2010. Kathmandu: Bird Conservation of Nepal and Department of National Parks and Wildlife Conservation; 2011.

Beuel S, Alvarez M, Amler E, Behn K, Kotze D, Kreye C, et al. A rapid assessment of anthropogenic disturbances in East African wetlands. Ecol Indic. 2016;67:684-92.

Bharti H, Sharma YP, Bharti M, Pfeiffer M. Ant species richness, endemicity and functional groups, along an elevational gradient in the Himalayas. Asian Myrmecol. 2013;5:79-101.

Bhattarai KR, Vetaas OR. Can Rapoport's rule explain tree species richness along the Himalayan elevation gradient, Nepal? Divers Distrib. 2006;12:373-8.

Bhattarai KR, Vetaas OR, Grytnes JA. Fern species richness along a central Himalayan elevational gradient, Nepal. J Biogeogr. 2004;31:389-400.

Bibby C, Burgess N, Hill D, Mustoe S. Bird census techniques (2nd edn.). San Diego, CA: Academic Press; 2001.

Bötsch Y, Tablado Z, Scherl D, Kéry M, Graf RF, Jenni L. Effect of recreational trails on forest birds: human presence matters. Front Ecol Evol. 2018;6:175.

Carnicer J, Brotons L, Stefanescu C, Peñuelas J. Biogeography of species richness gradients: linking adaptive traits, demography and diversification. Biol Rev. 2011;87:457-79.

Chen Z, He K, Cheng F, Khanal L, Jiang X. Patterns and underlying mechanisms of non-volant small mammal richness along two contrasting mountain slopes in southwestern China. Sci Rep. 2017;7:13277.

Chen Z, Li X, Song W, Li Q, Onditi K, Khanal L, et al. Small mammal species richness and turnover along elevational gradient in Yulong Mountain, Yunnan, Southwest China. Ecol Evol. 2020;10:2545-58.

Chettri B, Bhupathy S, Acharya BK. Distribution pattern of reptiles along an eastern Himalayan elevation gradient, India. Acta Oecol. 2010;36:16-22.

Colwell RK, Lees DC. The mid-domain effect: geometric constraints on the geography of species richness. Trends Ecol Evol. 2000;15:70-6.

Colwell RK, Rahbek C, Gotelli NJ. The mid-domain effect and species richness patterns: what have we learned so far? Am Nat. 2004;163:E1-23.

Currie DJ. Energy and large-scale patterns of animal-and plant-species richness. Am Nat. 1991;137:27-49.

de Bonilla EP-D, León-Cortés JL, Rangel-Salazar JL. Diversity of bird feeding guilds in relation to habitat heterogeneity and land-use cover in a human-modified landscape in southern Mexico. J Trop Ecol. 2012;28:369-76.

Dos Anjos L, Boçon R. Bird communities in natural forest patches in southern Brazil. Wilson Bull. 1999;111:397-414.

Dunn RR, McCain CM, Sanders NJ. When does diversity fit null model predictions? Scale and range size mediate the mid-domain effect. Glob Ecol Biogeogr. 2007a;16:305-12.

Dunn RR, Parker CR, Sanders NJ. Temporal patterns of diversity: assessing the biotic and abiotic controls on ant assemblages. Biol J Linn Soc. 2007b;91:191-201.

Fu C, Hua X, Li J, Chang Z, Pu Z, Chen J. Elevational patterns of frog species richness and endemic richness in the Hengduan Mountains, China: geometric constraints, area and climate effects. Ecography. 2006;29:919-27.

Gavashelishvili A, McGrady MJ. Breeding site selection by bearded vulture (Gypaetus barbatus) and Eurasian griffon (Gyps fulvus) in the Caucasus. Anim Conserv. 2006:9:159-70.
Gomes M, Rabaça JE, Godinho C, Ramos JA. Seasonal variation in bird species richness and abundance in Riparian Galleries in Southern Portugal. Acta Ornithol. 2017;52:69-79.

Grau O, Grytnes J-A, Birks HJB. A comparison of altitudinal species richness patterns of bryophytes with other plant groups in Nepal, Central Himalaya. J Biogeogr. 2007;34:1907-15.

Grimmett R, Inskipp C, Inskipp T, Baral HS. Birds of Nepal: Revised edition. London: Bloomsbury Publishing; 2016.

Halfwerk W, Holleman LJ, Lessells CM, Slabbekoorn H. Negative impact of traffic noise on avian reproductive success. J Appl Ecol. 2011;48:210-9.

Hamer KC, Hill JK. Scale-dependent effects of habitat disturbance on species richness in tropical forests. Conserv Biol. 2000;14:1435-40.

Hammer O, Harper DAT, Ryan PD. PAST: Paleontological statistics software package for education and data analysis. Palaeontol Electron. 2001;4:1-9.

Hawkins BA, Diniz-Filho JAF, Soeller SA. Water links the historical and contemporary components of the Australian bird diversity gradient. J Biogeogr. 2005:32:1035-42.

Hawkins BA, Diniz-Filho JAF, Jaramillo CA, Soeller SA. Climate, niche conservatism, and the global bird diversity gradient. Am Nat. 2007;170:S16-27.

Hawkins BA, Porter EE. Area and the latitudinal diversity gradient for terrestrial birds. Ecol Lett. 2001;4:595-601.

He X, Wang X, DuBay S, Reeve AH, Alström P, Ran J, et al. Elevational patterns of bird species richness on the eastern slope of Mt. Gongga, Sichuan Province, China. Avian Res. 2019;10:1.

Herzog SK, Kessler M, Bach K. The elevational gradient in Andean bird species richness at the local scale: a foothill peak and a high-elevation plateau. Ecography. 2005;28:209-22.

Hijmans RJ, Cameron SE, Parra JL, Jones PG, Jarvis A. Very high resolution interpolated climate surfaces for global land areas. Int J Climatol J R Meteorol Soc. 2005;25:1965-78.

Hu S, Niu Z, Chen Y, Li L, Zhang H. Global wetlands: potential distribution, wetland loss, and status. Sci Total Environ. 2017a;586:319-27.

Hu Y, Jin K, Huang Z, Ding Z, Liang J, Pan X, et al. Elevational patterns of nonvolant small mammal species richness in Gyirong Valley, Central Himalaya: evaluating multiple spatial and environmental drivers. J Biogeogr. 2017b;44:2764-77.

Hu Y, Ding Z, Jiang Z, Quan Q, Guo K, Tian L, et al. Birds in the Himalayas: what drives beta diversity patterns along an elevational gradient? Ecol Evol. 2018:8:11704-16.

Huang C, Li X, Khanal L, Jiang X. Habitat suitability and connectivity inform a co-management policy of protected area network for Asian elephants in China. PeerJ. 2019;7:e6791.

Hurlbert AH, Haskell JP. The effect of energy and seasonality on avian species richness and community composition. Am Nat. 2002;161:83-97.

Inskipp C, Inskipp T. Bird conservation priorities of the Annapurna Conservation Area. Report submitted to UNEP-WCMC/King Mahendra Trust for Nature Conservation/Annapurna Conservation Area Project; 2003.

Katuwal HB, Basnet K, Khanal B, Devkota S, Rai SK, Gajurel JP, et al. Seasonal changes in bird species and feeding guilds along elevational gradients of the Central Himalayas, Nepal. PLoS ONE. 2016;11:e0158362.

Khatiwada JR, Zhao T, Chen Y, Wang B, Xie F, Cannatella DC, et al. Amphibian community structure along elevation gradients in eastern Nepal Himalaya. BMC Ecol. 2019;19:1-11.

Kissling WD, Rahbek C, Böhning-Gaese K. Food plant diversity as broadscale determinant of avian frugivore richness. Proc R Soc B Biol Sci. 2007:274:799-808.

Koh CN, Lee PF, Lin RS. Bird species richness patterns of northern Taiwan: primary productivity, human population density, and habitat heterogeneity. Divers Distrib. 2006;12:546-54.

Krauczuk E, Baldo J. Contribuição para o conhecimento da avifauna de um fragmento de floresta com araucária em Misiones, Argentina. Atual Ornitól. 2004;119:6.

Li L, Wang Z, Zerbe S, Abdusalih N, Tang Z, Ma M, et al. Species richness patterns and water-energy dynamics in the drylands of Northwest China. PLOS ONE. 2013;8:e66450.

Machac A, Janda M, Dunn RR, Sanders NJ. Elevational gradients in phylogenetic structure of ant communities reveal the interplay of biotic and abiotic constraints on diversity. Ecography. 2011;34:364-71. 
Mallet-Rodrigues F, Parrini R, Rennó B. Bird species richness and composition along three elevational gradients in southeastern Brazil. Atual Ornitol. 2015;188:39-58.

Maphisa DH, Smit-Robinson H, Underhill LG, Altwegg R. Drivers of bird species richness within moist high-altitude Grasslands in Eastern South Africa. PLOS ONE. 2016;11:e0162609.

McCain CM. The mid-domain effect applied to elevational gradients: species richness of small mammals in Costa Rica. J Biogeogr. 2004;31:19-31.

McCain CM. Global analysis of bird elevational diversity. Glob Ecol Biogeogr. 2009;18:346-60.

McCarthy MJ, Radabaugh KR, Moyer RP, Muller-Karger FE. Enabling efficient, large-scale high-spatial resolution wetland mapping using satellites. Remote Sens Environ. 2018;208:189-201.

Mittermeier RA. Hotspots revisited. Mexico: Cemex; 2004.

Muhammad SI, Ramli R, Then AY. Seasonality, habitat type and locality influenced bird assemblage structure in Nigeria. Ostrich. 2018;89:221-31.

Murphy GEP, Romanuk TN. A meta-analysis of declines in local species richness from human disturbances. Ecol Evol. 2014:4:91-103.

Nam H-Y, Kim E-M, Choi C-Y, Kang C-W. Avifauna of Gungdae Oreum and its seasonal changes in the Jeju Eastern Oreum Group in Jeju Island, Korea. J Asia Pac Biodivers. 2019;12:515-21.

Neupane J, Khanal L, Chalise MK. Avian diversity in Kaligandaki River basin, Annapurna Conservation Area, Nepal. Int J Ecol Environ Sci. 2020;46:99-110.

NTNC-ACAP. National Trust for Nature Conservation- Annapurna Conservation Area Project. https://ntnc.org.np/project/annapurna-conservation-areaproject-acap. Accessed 8 Aug 2020.

Oksanen J, Blanchet F, Kindt R, Legendre P, Minchin PR, O'Hara RB, et al. Vegan: community ecology package. 2013. http://cran.r-project.org/. Accessed 25 Mar 2018.

Olson VA, Davies RG, Orme CD, Thomas GH, Meiri S, Blackburn TM, et al. Global biogeography and ecology of body size in birds. Ecol Lett. 2009:12:249-59.

Oommen MA, Shanker K. Elevational species richness patterns emerge from multiple local mechanisms in Himalayan woody plants. Ecology. 2005;86:3039-47.

Pan X, Ding Z, Hu Y, Liang J, Wu Y, Si X, et al. Elevational pattern of bird species richness and its causes along a central Himalaya gradient, China. PeerJ. 2016;4:e2636

Patterson BD, Stotz DF, Solari S, Fitzpatrick JW, Pacheco V. Contrasting patterns of elevational zonation for birds and mammals in the Andes of southeastern Peru. J Biogeogr. 1998:25:593-607.

Paudel PK, Šipoš J. Conservation status affects elevational gradient in bird diversity in the Himalaya: a new perspective. Glob Ecol Conserv. 2014;2:338-48.

Pavlacky DC Jr, Possingham HP, Goldizen AW. Integrating life history traits and forest structure to evaluate the vulnerability of rainforest birds along gradients of deforestation and fragmentation in eastern Australia. Biol Conserv. 2015;188:89-99.

Peters MK, Hemp A, Appelhans T, Behler C, Classen A, Detsch F, et al. Predictors of elevational biodiversity gradients change from single taxa to the multi-taxa community level. Nat Commun. 2016;7:13736.

Petit DR, Petit LJ, Saab VA, Martin TE. Fixed radius point counts in forests: factors influencing effectiveness and efficiency. In: Ralph CJ, Sauer JR, Droege S, editors. Monitoring bird populations by point counts. Gen. Tech. Rep. PSW-GTR-149. Albany: US Department of Agriculture, Forest Service, Pacific Southwest Research Station; 1995. p. 49-56.

Price TD, Hooper DM, Buchanan CD, Johansson US, Tietze DT, Alström P, et al. Niche filling slows the diversification of Himalayan songbirds. Nature. 2014;509:222-5.

Rahbek C. The elevational gradient of species richness: a uniform pattern? Ecography. 1995;18:200-5.

Rahbek C. The role of spatial scale and the perception of large-scale speciesrichness patterns. Ecol Lett. 2005:8:224-39.

Ralph CJ, Droege S, Sauer JR. Managing and monitoring birds using point counts: standards and applications. In: Ralph CJ, Sauer JR, Droege S, editors. Monitoring bird populations by point counts. Gen. Tech. Rep.
PSW-GTR-149. Albany: US Department of Agriculture, Forest Service, Pacific Southwest Research Station; 1995. p. 161-8.

Rana SK, Gross K, Price TD. Drivers of elevational richness peaks, evaluated for trees in the east Himalaya. Ecology. 2019;100:e02548.

R-Core-Team. R: a language and environment for statistical computing. Vienna, Austria: R Foundation for Statistical Computing; 2017. https://www.Rproject.org/.

Reijnen R, Foppen R, Braak CT, Thissen J. The effects of car traffic on breeding bird populations in woodland. III. Reduction of density in relation to the proximity of main roads. J Appl Ecol. 1995;32:187-202.

Rokaya MB, Münzbergová Z, Shrestha MR, Timsina B. Distribution patterns of medicinal plants along an elevational gradient in central Himalaya, Nepal. J Mt Sci. 2012;9:201-13.

Ruggiero A, Hawkins BA. Why do mountains support so many species of birds? Ecography. 2008;31:306-15.

Sanders NJ, Rahbek C. The patterns and causes of elevational diversity gradients. Ecography. 2012;35:1-3.

Sarkar MS, Pandey A, Singh G, Lingwal S, John R, Hussain A, et al. Multiscale statistical approach to assess habitat suitability and connectivity of common leopard (Panthera pardus) in Kailash Sacred Landscape, India. Spat Stat. 2018;28:304-18.

Sekercioglu $\mathrm{CH}$. Bird functional diversity and ecosystem services in tropical forests, agroforests and agricultural areas. J Ornithol. 2012;153:153-61.

Shoo LP, Williams SE, Hero J-M. Climate warming and the rainforest birds of the Australian Wet Tropics: using abundance data as a sensitive predictor of change in total population size. Biol Conserv. 2005;125:335-43.

Shrestha UB, Gautam S, Bawa KS. Widespread climate change in the Himalayas and associated changes in local ecosystems. PLoS ONE. 2012;7:e36741.

Shwartz A, Shirley S, Kark S. How do habitat variability and management regime shape the spatial heterogeneity of birds within a large Mediterranean urban park? Landsc Urban Plan. 2008:84:219-29.

Somveille M, Rodrigues ASL, Manica A. Energy efficiency drives the global seasonal distribution of birds. Nat Ecol Evol. 2018;2:962-9.

Stouffer PC, Bierregaard RO Jr. Use of Amazonian forest fragments by understory insectivorous birds. Ecology. 1995:76:2429-45.

Thakuri S, Pokhrel GK. Herpetofaunal diversity in Manaslu Conservation Area, Nepal. Our Nat. 2017;14:99-106.

Tzortzakaki O, Kati V, Kassara C, Tietze DT, Giokas S. Seasonal patterns of urban bird diversity in a Mediterranean coastal city: the positive role of open green spaces. Urban Ecosyst. 2017;21:27-39.

Van Driem G. From the Dhaulagiri to Lappland. J Indian Res. 2014;2:2-19.

Vetaas OR, Grytnes JA. Distribution of vascular plant species richness and endemic richness along the Himalayan elevation gradient in Nepal. Glob Ecol Biogeogr. 2002;11:291-301.

Voskamp A, Baker DJ, Stephens PA, Valdes PJ, Willis SG. Global patterns in the divergence between phylogenetic diversity and species richness in terrestrial birds. J Biogeogr. 2017;44:709-21.

Werema C, Howell KM. Seasonal variation in diversity and abundance of understorey birds in Bunduki Forest Reserve, Tanzania: evaluating the conservation value of a plantation forest. Ostrich. 2015;87:89-93.

Wu Y, Colwell RK, Rahbek C, Zhang C, Quan Q, Wang C, et al. Explaining the species richness of birds along a subtropical elevational gradient in the Hengduan Mountains. J Biogeogr. 2013;40:2310-23.

Xie Y, Zhang A, Welsh W. Mapping wetlands and Phragmites using publically available remotely sensed images. Photogramm Eng Remote Sens. 2015;81:69-78

Zhang D-C, Zhang Y-H, Boufford DE, Sun H. Elevational patterns of species richness and endemism for some important taxa in the Hengduan Mountains, southwestern China. Biodivers Conserv. 2009;18:699-716.

Zhang J, Kissling WD, He F, Patten M. Local forest structure, climate and human disturbance determine regional distribution of boreal bird species richness in Alberta, Canada. J Biogeogr. 2013:40:1131-42. 